Proceedings

\title{
A Novel Transparent pH Sensor Based on a Nanostructured ITO Electrode Coated with [3,3'-Co(1,2-C2B9H11)2]-Doped Poly(pyrrole) +
}

\author{
Raquel Pruna ${ }^{1, *}$, Francisco Palacio ${ }^{1}$, Isabel Fuentes ${ }^{2}$, Clara Viñas ${ }^{2}$, Francesc Teixidor ${ }^{2}$ and \\ Manuel López ${ }^{1}$ \\ 1 Departament d'Enginyeria Electrònica i Biomèdica, Universitat de Barcelona, E-08028 Barcelona, Spain; \\ fpalacio@el.ub.edu (F.P.); mlopez@el.ub.edu (M.L.) \\ 2 Institut de Ciència de Materials de Barcelona, ICMAB-CSIC, E-08193 Bellaterra, Spain; \\ ifuentes@icmab.es (I.F.); clara@icmab.es (C.V.); teixidor@icmab.es (F.T.) \\ * Correspondence: rpruna@el.ub.edu; Tel.: +34-934-039-876 \\ † Presented at the Eurosensors 2018 Conference, Graz, Austria, 9-12 September 2018.
}

Published: 23 November 2018

\begin{abstract}
A novel transparent and nanostructured ion-sensitive electrode based on indium tin oxide (ITO) coated with cobaltbis(dicarbollide)-doped poly(pyrrole) (PPy) is presented in this work. This metallacarborane-doped PPy was used as conducting polymer due to its high stability and chemical resistance. The ion-sensitive electrode was coupled to a miniaturized and low-cost potentiostat, in a final autonomous kit for potentiometric determination of $\mathrm{pH}$. Qualitative calibration of the system revealed Nernstian behavior, resulting promising for novel point-of-care biomedical applications.
\end{abstract}

Keywords: indium tin oxide (ITO); metallacarboranes; boron compounds; $\mathrm{pH}$ sensor; potentiometric sensor; potentiometry; nanoscience; poly(pyrrole) (PPy); intrinsically conducting polymer (ICP)

\section{Introduction}

Commercial-based $\mathrm{pH}$ sensors (glass electrodes) are becoming obsolete in many challenging applications such as biomedical and environmental monitoring, for they are constructed around liquid-filled glass membranes that imply limitations in size and rigidity. To overcome these limitations, solid-state $\mathrm{pH}$ sensors based on various organic materials were suggested in the past, which allowed the mass-production and miniaturization of flexible electrodes. Still a challenge in $\mathrm{pH}$ sensors is optical transparency, which would allow simultaneous monitoring of potentiometry and optical features (e.g., fluorescence or chemiluminescence in some biochemical systems). Indeed, some important biomedical applications [1] have recently been reported in these terms.

Parallelly, many efforts have been devoted to the development of sensors based on intrinsically conducting polymers (ICPs), for they are highly stable and conductive, and also due to their ease of preparation. In this sense, devices for metal ion detection [2,3], humidity sensors [4] and nitrateselective sensors [5] based on ICPs have been widely reported. Poly(pyrrole) (PPy) is one of the most stable of all known ICPs and is also one of the easiest to synthesize. Due to the latter and also to its great technological potential, PPy has attracted much attention in many electrochemical applications. Two doping structures for PPy were proposed in the past: (1) a PPy structure with the pyrrole unit protonated at the $\beta$ carbon would perform as $\mathrm{H}^{+}$sensor by enabling deprotonation and subsequent de-doping; and (2) a PPy insulator film as the basis of a metal/insulator/metal device for 
electroinactive $\mathrm{pH}$ sensor. However, the practical implementation of the latter is not competitive with the commercial glass $\mathrm{pH}$ sensor, especially in terms of cost and ease of use.

In this work, the use of transparent nanostructured electrodes based on indium tin oxide (ITO) as a novel electrochemical platform for $\mathrm{pH}$ determination is proposed. We describe a fully glass-free potentiometric $\mathrm{pH}$ sensor based on a PPy-modified electrode. The cobaltbis(dicarbollide) anion ([3,3$\left.\mathrm{Co}(1,2-\mathrm{C} 2 \mathrm{~B} 9 \mathrm{H} 11) 2]^{-}\right)$was chosen as doping agent for the PPy films due to its high chemical resistance $[7,8]$ and advantages over other common dopant anions elsewhere described [9]. The development of this transparent glass-free electrode generation will be useful in developing $\mathrm{pH}$ sensors avoiding the typical problems (fragility, response loss in organic media) in commercial glass-based electrodes.

\section{Materials and Methods}

\subsection{Fabrication of Transparent Nanostructured Electrode}

The nanostructured ITO electrodes were grown by electron beam evaporation on a transparent substrate with a Pfeiffer Vacuum Classic 500. Commercial ITO pellets with a concentration of 90/10 $\%$ wt. In $2 \mathrm{O}_{3} / \mathrm{SnO}_{2}$ were purchased from Neyco, France. Substrate temperature was set at $300{ }^{\circ} \mathrm{C}$, and the deposition rate was set at a constant value of $1 \AA \mathrm{s}^{-1}$ during $30 \mathrm{~min}$. The samples were further annealed at $600{ }^{\circ} \mathrm{C}$ during $1 \mathrm{~h}$ in N2 atmosphere after the evaporation process, in order to promote the total crystallization of ITO, leading to an enhancement of the electrical conductivity and optical transparency.

\subsection{Electropolymerization of Co(1,2-C2B9H11)2]-Doped Pyrrole}

The cobaltbis(dicarbollide)-doped PPy films were prepared galvanostatically on ITO electrodes in acetonitrile solution. A three-electrode system was used to electropolymerize a solution of $100 \mathrm{mM}$ Pyrrole and $50 \mathrm{mM}\left[3,3^{\prime}-\mathrm{Co}\left(1,2-\mathrm{C}_{2} \mathrm{~B}_{9} \mathrm{H}_{11}\right)_{2}\right]^{-}$in acetonitrile by $\mathrm{CV}$ between $1.2 \mathrm{~V}$ and $-0.9 \mathrm{~V}$, at $100 \mathrm{mV} \mathrm{s}^{-1}$ for three cycles to keep the electrode optical transparency.

\subsection{Monitoring System and Electrode Calibration}

The potential response behavior of this novel transparent, conductive and nanostructured film was investigated in aqueous $\mathrm{pH}$ buffers prepared from $\mathrm{HCl}$ and $\mathrm{NaOH}$ solutions. A self-developed low-cost and miniaturized potentiostatic device was used for two-electrode potentiometry measurements, with the modified ITO film as ion-sensitive working electrode with respect to a $\mathrm{Ag} / \mathrm{AgCl}(\mathrm{KCl}$ sat.) reference electrode.

\section{Results and Discussion}

\subsection{Electrode Characterization}

A scanning electron microscopy (SEM) image of the ITO nanowhiskers is shown in Figure 1a. This image reveals dense nanowires with mean diameter around $30 \mathrm{~nm}$. The morphology of the wires (long stick and seed at the tip) and the film composition reveal that the nanostructuration was produced by the self-vapor-liquid-solid (self-VLS) mechanism. The electrochemical surface area provided by such nanostructured electrode was proved to be an order of magnitude higher (in a projected area around $1 \mathrm{~cm}^{2}$ ) than its thin film counterpart [10]. This enhanced surface area has proved useful for amperometric and impedance sensors in terms of sensitivity and limit of detection. 


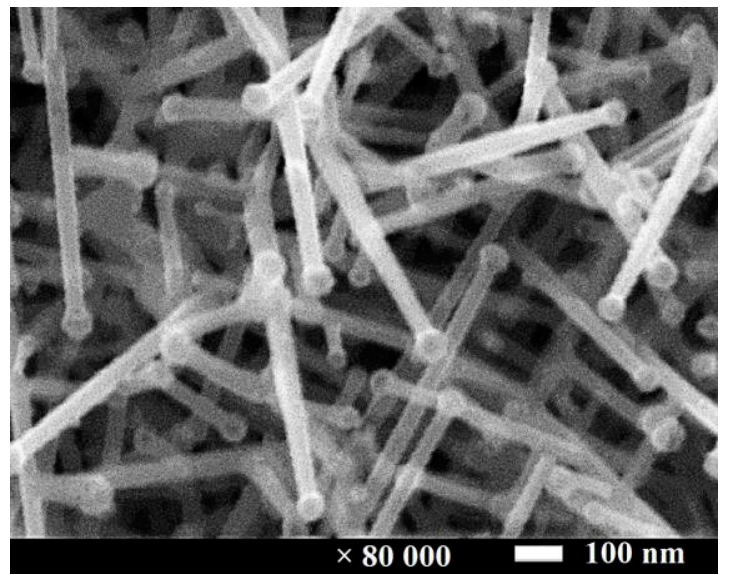

(a)

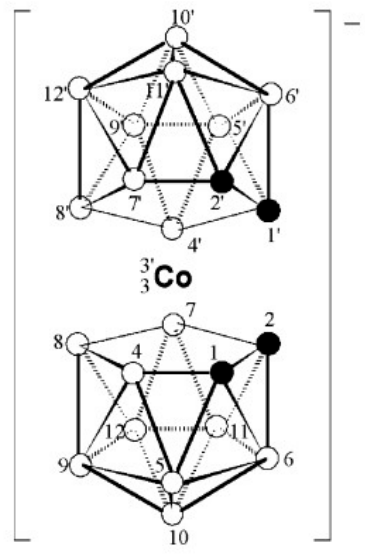

(b)

Figure 1. (a) SEM micrograph of a transparent nanostructured ITO electrode; (b) Chemical structure of the cobaltabis (dicarbollide) [3,3'-Co(1,2-C2B9H11)2 $]^{-}$anion.

\subsection{Electrode Calibration}

The surface was coated with a functional conducting polymer via electrochemical polymerization by cyclic voltammetry $(\mathrm{CV})$. The polymer was doped with cobaltbis(dicarbollide) anion, whose chemical structure is shown in Figure 1b. The polymerization was performed in three voltammetric cycles between $-0.9 \mathrm{~V}$ and $1.2 \mathrm{~V}$ (Figure $2 \mathrm{a}$ ).

The potential response behavior of this novel electrode was investigated in $\mathrm{pH}$ buffer. The potentiometric characteristic of this film is indicative of quasi-Nernstian response $(50 \mathrm{mV}$ per $\mathrm{pH}$ unit), as can be observed in Figure $2 \mathrm{~b}$. The film showed a linearity range from $\mathrm{pH} 1$ to 14 , although further measurements should contribute to increase the correlation coefficient $(>0.85)$.

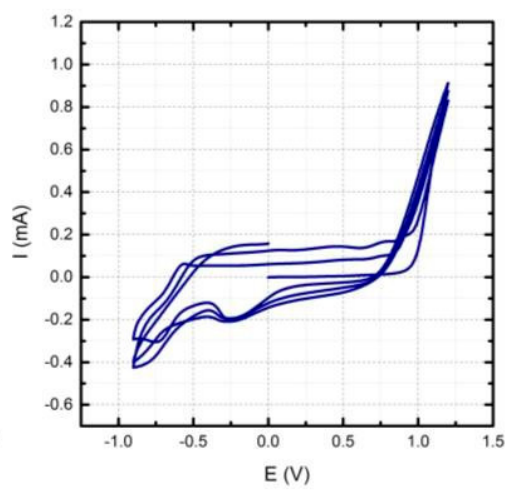

(a)

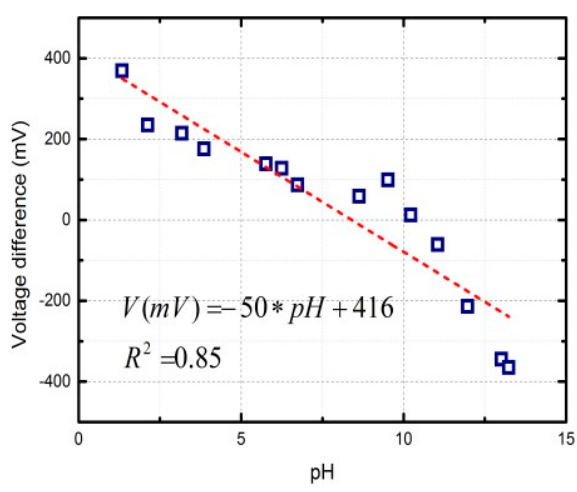

(b)

Figure 2. (a) Chemical structure of the cobaltabis(dicarbollide) $\left[3,3^{\prime}-\mathrm{Co}(1,2-\mathrm{C} 2 \mathrm{~B} 9 \mathrm{H} 11) 2\right]^{-}$anion; (b) Nernstian evolution of the voltage measured by the ion-sensitive electrode with the $\mathrm{pH}$ of solution, with linear behavior along the whole $\mathrm{pH}$ range.

\section{Conclusions}

In summary, the preliminary results presented in this work point towards a new promising transparent ion-sensitive film coupled to a low-cost and miniaturized electronic system to achieve a fully autonomous measurement kit for precise potentiometric measurements in point-of-care medical environments. Along a set of works concluding in the present one, we presented a complete structural and electrochemical characterization of transparent nanostructured ITO-based electrodes and several applications as impedance, amperometric and potentiometric sensors. With all, this transparent nanostructured electrode proved suitable for electrochemical impedance spectroscopy and amperometric detection of biochemical species, and for $\mathrm{pH}$ measurement. In the near future it will 
be tested for monoprotic titrations of strong alkalis and strong acids, and weak bases with strong acids. This will lead to a new generation of highly sensitive $\mathrm{pH}$ sensors, avoiding the typical problems (fragility, response loss in organic media) in commercial glass-based electrodes, and suitable for being coupled to optical detection systems due to their high transparency to visible and infrared wavelengths.

Author Contributions: M.L., F.T. and R.P. conceived and designed the experiments; I.F. and R.P. performed the experiments; F.P., F.T. and C.V. contributed reagents/materials/analysis tools; R.P. wrote the paper.

Acknowledgments: This work has been supported by the Spanish Ministerio de Economía y Competitividad (CTQ2016-75150-R) and the Generalitat de Catalunya (2014/SGR/149). R.P. acknowledges an FPU grant (FPU15/00771) from the Spanish Ministerio de Educación, Cultura y Deporte.

Conflicts of Interest: The authors declare no conflict of interest. The founding sponsors had no role in the design of the study; in the collection, analyses, or interpretation of data; in the writing of the manuscript, and in the decision to publish the results.

\section{References}

1. Rahimi, R.; Brener, U.; Chittiboyina, S.; Soleimani, T.; Detwiler, D.A.; Lelièvre, S.A.; Ziaie, B. Laser-enabled fabrication of flexible and transparent $\mathrm{pH}$ sensor with Near-Field Communication for in-situ monitoring of wound infection. Sens. Actuators B Chem. 2018, 267, 198-207, doi:10.1016/j.snb.2018.04.

2. Barisci, J.N.; Murray, P.; Small, C.J.; Wallace, G.G. Studies of the preparation and analytical application of polypyrrole-coated microelectrodes for determination of aluminum. Electroanalysis 1996, 8, 330-335, doi:10.1002/elan.1140080406.

3. Arrigan, D.W.; Lowens, M.J. Polypyrrole films doped with an electroactive sulfonated chelating reagent: Electrochemical characterization and the detection of metal ions. Electroanalysis 1999, 11, 647-652, doi:10.1002/(SICI)1521-4109(199907)11:9<647::AID-ELAN647>3.0.CO;2-N.

4. Ogura, K.; Shiigi, H.; Nakayama, M. A New Humidity Sensor Using the Composite Film Derived from Poly(o-phenylenediamine) and Poly(vinyl alcohol). J. Electrochem. Soc. 1996, 143, 2925-2930, doi:10.1149/1.1837128.

5. Sun, B.; Fitch, P.G. Nitrate ion-selective sensor based on electrochemically prepared conducting polypyrrole films. Electroanalysis 1997, 9, 494-497, doi:10.1002/elan.1140090612.

6. Masalles, C.; Borros, S.; Vinas, C.; Teixidor, F. Simple PVC-PPy electrode for pH measurement and titrations. Anal. Bioanal. Chem. 2002, 3724, 513-518, doi:10.1007/s00216-001-1221-7.

7. Viñas, C.; Gomez, S.; Bertran, J.; Teixidor, F.; Dozol, J.F.; Rouquette, H. New Polyether-Substituted Metallacarboranes as Extractants for 137Cs and 90Sr from Nuclear Wastes. Inorg. Chem. 1998, 37, 3640-3643, doi:10.1021/ic971467m.

8. Viñas, C.; Gomez, S.; Bertran, J.; Teixidor, F.; Dozol, J.F.; Rouquette, H. Cobaltabis (dicarbollide) derivatives as extractants for europium from nuclear wastes. Chem. Commun. 1998, 2, 191-192, doi:10.1039/A707835H.

9. Masalles, C.; Borros, S.; Vinas, C.; Teixidor, F. Are low-coordinating anions of interest as doping agents in organic conducting polymers? Adv. Mater. 2000, 1216, 1199-1202. doi:10.1002/15214095(200008)12:16<1199::AID-ADMA1199>3.0.CO;2-W.

10. Pruna, R.; Palacio, F.; López, M.; Pérez, J; Mir, M.; Blázquez, O.; Hernández, S.; Garrido, B. Electrochemical characterization of organosilane-functionalized nanostructured ITO surfaces. Appl. Phys. Lett. 2016, 109, 063109, doi:10.1063/1.4960734.

(C) 2018 by the authors. Licensee MDPI, Basel, Switzerland. This article is an open access article distributed under the terms and conditions of the Creative Commons Attribution (CC BY) license (http://creativecommons.org/licenses/by/4.0/). 